\title{
As Políticas Públicas no Processo de Inovação na Indústria Farmacêutica: $O$ caso da vacina contra a Hepatibe B
}

\author{
Claudio Henrique Braga Farinaz?o* \\ José Wladimir Freitas da Fonseca**
}

\section{Introdução}

Nos últimos anos, com o avanço das biotecnologias nos processos produtivos, tornou-se imprescindível o entendimento de como esses processos podem se tornar cada vez mais eficientes e inovadores. A ciência, a técnica e a produção industriais, situados no processo de inovação em biotecnologias, passaram a desempenhar um papel de destaque. $\mathrm{O}$ Estado, as empresas privadas e as instituições públicas de pesquisa têm um papel fundamental na questão desse processo evolutivo. São as áreas responsáveis por oferecer e fazer com que esse conhecimento se desenvolva a ponto de gerar benefícios e riqueza para a nação homogeneamente.

O presente artigo tem por objetivo central apresentar de que forma o processo de inovação ocorre nas biotecnologias (precisamente na indústria farmacêutica) tendo como estudo de caso o desenvolvimento da vacina recombinante contra a Hepatite B, desenvolvida pelo Instituto Butantan.

Assim, na primeira seção identifica-se o papel do Estado como articulador do processo de inovação, através de políticas públicas para o estabelecimento de um ambiente favorável a esse desenvolvimento. Na segunda seção demonstra-se o processo de inovação através da relação que se estabelece entre o conhecimento, a técnica e a indústria no caso da vacina contra a hepatite B e finalizando, a terceira seção sumaria as principais conclusões.

\section{O Estado como articulador do processo de inovação nas biotecnologias no} Brasil: a importância das políticas públicas.

Desde que Jim Watson e James Crick identificaram a estrutura da dupla hélice de DNA, em 1953, passando-se a compreender a relação entre a estrutura de DNA e a formação e funcionamento dos organismos vivos, tem-se observado um avanço na biotecnologia. Mas foi a partir da década de 1970, quando David Jackson e Robert Symons desenvolveram a técnica do DNA recombinante, é que ficou evidente a possibilidade de aplicação do

\footnotetext{
* Economista pela Universidade Federal do Paraná (UFPR). Endereço eletrônico: claudiofarinazzo@yahoo.com.br

** Professor da Universidade Federal do Paraná (UFPR) e Doutor em Economia pela Université de Toulouse IFrança. Endereço Eletrônico: wladi@,ufpr.br
} 
conhecimento científico e da técnica, na produção industrial. Com isso, o campo dos produtos farmacêuticos se mostrou com grande potencial de aplicação do processo inovativo nas biotecnologias.

Nos países desenvolvidos, passou-se a dar destaque à aplicação da biotecnologia na área de saúde, através de programas nacionais de vacinação. Com grandes investimentos em P\&D de empresas privadas, para atender às demandas das políticas nacionais de saúde.

No Brasil, com a criação do Programa Nacional de Imunizações (PNI) em 1973, o qual tinha por objetivo ampliar a aplicação das vacinas contra as principais doenças (ex.: poliomielite, tuberculose, sarampo, difteria, tétano, coqueluche, raiva, e febre amarela), deu-se o primeiro passo em direção ao desenvolvimento da produção nacional de vacinas.

O governo brasileiro, através de uma política de imunização envolvendo diversos setores, como a sociedade civil, Ministério da Saúde, governos estaduais e municipais e as forças armadas, implementou as seguintes medidas (Gadelha e Azevedo, 2003) ${ }^{38}$ : Estruturação de uma rede de frio $^{39}$ no país para viabilizar a vacinação em um território de dimensões continentais; capacitação de recursos humanos para operacionalizar as ações de vacinação em massa; criação de centros de referência em imunobiológicos especiais, que atualmente cobrem $89 \%$ das unidades federadas, viabilizando a vacinação de grupos especiais (imunodeprimidos, entre outros); criação de um sistema de informação e de vigilância epidemiológica em saúde, possibilitando a avaliação de indicadores de cobertura, de resposta imunológica, reações adversas e de evolução epidemiológica no âmbito das distintas regiões; e o estabelecimento de controle de qualidade das vacinas produzidas no país e de outros imunobiológicos, realizado pelo Instituto Nacional de Controle de Qualidade em Saúde (INCQS), da Fundação Oswaldo Cruz.

Diferentemente dos países mais desenvolvidos, o principal financiador dos gastos com pesquisa e desenvolvimento é o próprio Estado. Isso se deve ao fato de o desenvolvimento científico no país ter partido de iniciativas do próprio governo através das universidades e centros de pesquisa financiados pelo governo federal. Como se pode observar pela Tabela 1 , o setor produtivo no Brasil tem uma participação de somente $20 \%$ no total de

\footnotetext{
38 Gadelha, C., Azevedo, N. Inovação em vacinas no Brasil: experiência recente e constrangimentos estruturais. Disponível em: www.scielo.br/pdf/hcsm/v10s2/a12v10s2.pdf. Acesso em 01 out. 2006.

${ }^{39}$ A Rede de Frio, ou Cadeia de Frio, é o processo de armazenamento, conservação, manipulação, distribuição e transporte dos imunobiológicos do Programa Nacional de Imunizações (PNI), desde o laboratório produtor até o momento em que a vacina é administrada. (Ministério da Saúde, 2003).
} 
gastos com P\&D, enquanto que a média dos outros países apontados abaixo (excetuando-se Israel), é de aproximadamente $81 \%$ dos gastos sendo financiados pela iniciativa privada.

\begin{tabular}{|c|c|c|}
\hline PAÍS & ANO & PARTICIPAÇÃO \\
\hline EUA & 1990 & $86 \%$ \\
\hline JAPÃO & 1988 & $89 \%$ \\
\hline ALEMANHA & 1990 & $89 \%$ \\
\hline FRANÇA & 1990 & $73 \%$ \\
\hline REINO UNIDO & 1988 & $77 \%$ \\
\hline ITÁLIA & 1990 & $70 \%$ \\
\hline HOLANDA & 1988 & $80 \%$ \\
\hline SUÍÇA & 1986 & $71 \%$ \\
\hline SUÉCIA & 1989 & $90 \%$ \\
\hline BRASIL & 1990 & $20 \%$ \\
\hline BÉLGICA & 1988 & $89 \%$ \\
\hline CORÉIA DO SUL & 1989 & $81 \%$ \\
\hline ISRAEL & 1989 & $22 \%$ \\
\hline
\end{tabular}

Como ressalta Cruz (2000), “Ao focalizar-se a atenção quase que exclusivamente no componente acadêmico do sistema, deixa-se de lado aquele que é o componente capaz de transformar ciência em riqueza, que é o setor empresarial”. Aí reside o problema da estratégia de desenvolvimento econômico adotada, num primeiro momento, no Brasil. Não há uma interação entre os três objetos já apontados como fundamentais para o perfeito desenvolvimento da inovação: conhecimento - técnica - indústria. Conforme ilustrado por Mignot e Poncet (2002) na Tabela 2.

Tabela 2. Os Três Níveis de Implicação no Movimento da Industrialização do Conhecimento

\begin{tabular}{llll}
\hline & Público & Público/Privado & Privado \\
\hline Organização & Instituições de Pesquisa & Estrutura & Industrial \\
Produção & Conhecimento & Técnica & Bem Econômico \\
Apoio & Publicação & Finalização & Inovação \\
\hline
\end{tabular}

Fonte: Mignot e Poncet (2002)

Com a criação do Programa Nacional de Biotecnologia (PRONAB), em 1981, fica evidente o foco desse programa na qualificação de novos profissionais, deixando-se de lado as possíveis aplicações industriais. O foco era a produção de conhecimento científico, através de 
treinamento e desenvolvimento das técnicas de engenharia genética, com a contratação de especialistas estrangeiros e concessão de bolsas de estudo para pós-graduação no exterior.

Segundo Mignot e Poncet (2002), as políticas públicas incitam o desaparecimento de lacunas entre as instituições de pesquisa e as companhias, assim como o grande potencial de crescimento dos mercados de agricultura e produtos farmacêuticos encorajam os governos a intervir para apoiar as atividades domésticas.

Nesse sentido, foi a partir de 1985, com a criação do Programa de Auto-Suficiência Nacional em Imunobiológicos (PASNI), que o Estado brasileiro assumiu um papel articulador da produção industrial de vacinas. O objetivo do programa era fortalecer o parque nacional de produção de imunobiológicos ${ }^{40}$. Além de políticas de produção de imunobiológicos que focaram numa melhora na oferta de vacinas e soros que eram obtidos, em sua maioria, através de importações. Com investimentos em torno de 150 milhões de dólares, entre 1985 e 1999, na rede de laboratórios oficiais (destacando-se Instituto Butantan, Instituto de Tecnologia do Paraná e Instituto de Tecnologia em Imunobiológicos - Bio Maguinhos/Fiocruz), o objetivo era a "recuperação da infra-estrutura, a modernização de instalações e equipamentos, a construção de novas unidades laboratoriais, a capacitação de profissionais especializados e, ainda, o desenvolvimento de tecnologia nacional e transferência de tecnologia para a produção de novas vacinas". (Ministério da Saúde, 2003). Portanto, o Estado passou a ser o maior cliente e o maior produtor na área de imunobiológicos.

Segundo o Ministério, as propostas para o setor farmacêutico estão baseadas em pesquisa e desenvolvimento realizados no Brasil; é importante o incentivo à internalização das atividades de P\&D; estímulo à produção doméstica de fármacos; fortalecer o programa de genéricos; explorar a biodiversidade; e estimular os laboratórios públicos.

Em seguida, o governo destaca o importante papel que os laboratórios públicos têm no desenvolvimento e criação de novos fármacos com a possibilidade de licenciá-los para outros laboratórios ou empresas de fármacos. Enfatiza a expansão do Programa de Apoio à Produção de Registro de Medicamentos genéricos, através da ampliação do crédito.

Por fim, destaca-se que é necessária uma coordenação entre a política de saúde e as políticas de regulação, onde os mercados seriam monitorados com respeito a preços e

\footnotetext{
40 Os imunobiológicos são produtos farmacêuticos, geralmente na forma de soro ou vacina, utilizados para a obtenção de imunização passiva ou ativa respectivamente. São compostos por microorganismos vivos atenuados. Produtos que, quando administrados ao hospedeiro, fornecem, induzem ou modificam uma resposta imune para um alvo químico ou entidade biológica.
} 
concentração, sendo aplicadas penalidades contra as condutas anticompetitivas. Neste sentido, de acordo com o MDICE (2006), as ações do governo com respeito à saúde pública serão balizadas da seguinte maneira: estimular a geração e controle de tecnologias e a conseqüente produção nacional de produtos estratégicos na área de saúde humana para posicionar competitivamente a bioindústria brasileira na comunidade biotecnológica internacional, com potencial para gerar novos negócios; expandir suas exportações; integrar-se à cadeia de valor; e estimular novas demandas por produtos e processos inovadores.

Com relação à produção de vacinas, o governo tem por objetivos investir em infraestrutura que irá apoiar a geração, desenvolvimento e comercialização, além da produção das vacinas consideradas prioritárias. Através do SUS (Sistema único de Saúde), comprar esses produtos para fortalecer a indústria nacional. De acordo com o Ministério da Saúde, os custos estimados para que o Brasil se torne auto-suficiente em vacina, baseados nos três maiores laboratórios nacionais produtores de vacinas, estão na ordem de $\mathrm{R} \$ 732$ milhões, divididos da seguinte maneira:

Tabela 3. Custos estimados para o Brasil atingir auto-suficiência em vacinas

\begin{tabular}{l|l|l}
\hline \multirow{2}{*}{ Instituição } & Área de Investimento & Custo \\
\cline { 2 - 3 } & Apoio a infra-estrutura nova (em 5 anos) & $\mathrm{R} \$ 235$ milhões \\
\cline { 2 - 3 } & Apoio a infra-estrutura já existente (em 3 anos) & $\mathrm{R} \$ 65$ milhões \\
\cline { 2 - 3 } & $\begin{array}{l}\text { Gastos estimados com DT \& I (pessoal, } \\
\text { manutenção de laboratórios, equipamentos, serviços } \\
\text { tecnológicos e aquisição de tecnologias) - em 10 } \\
\text { anos }\end{array}$ & $\mathrm{R} \$ 252$ milhões \\
\hline BUTANTAN & Custos para a produção de vacinas & $\mathrm{R} \$ 173$ milhões \\
\hline TECPAR & Custos para a produção de vacinas & $\mathrm{R} \$ 7,1$ milhões \\
\hline TOTAL & & $\mathrm{R} \$ 732$ milhões \\
\hline Fonte: MDICE - Fórum de Competitividade de Biotecnologia (2006) &
\end{tabular}

Com isso o governo brasileiro espera, através de planejamento e orientação dos programas de pesquisa e de suas políticas, tornar o ambiente de produção de vacinas mais dinâmico e fortalecido para o jogo da concorrência mundial. Espera-se que o trabalho dos cientistas seja voltado para as necessidades do mercado e, que os resultados científicos sirvam como padrão para a produção industrial (Mignot e Poncet, 2002).

Verifica-se pelo gráfico 1, que demonstra a relação entre número de casos confirmados e a cobertura vacinal contra a Hepatite B de menores de 1 ano de idade, que essas duas variáveis são inversamente proporcionais. E que a cobertura da vacinação está em 
torno de 90\% com uma diminuição cada vez mais acentuada no número de casos confirmados de Hepatite B.

Gráfico 1. Hepatite B - Número de Casos Confirmados X Cobertura Vacinal de Menores de 1 Ano de Idade em Rotina com a Terceira Dose - Brasil, 1993-2002

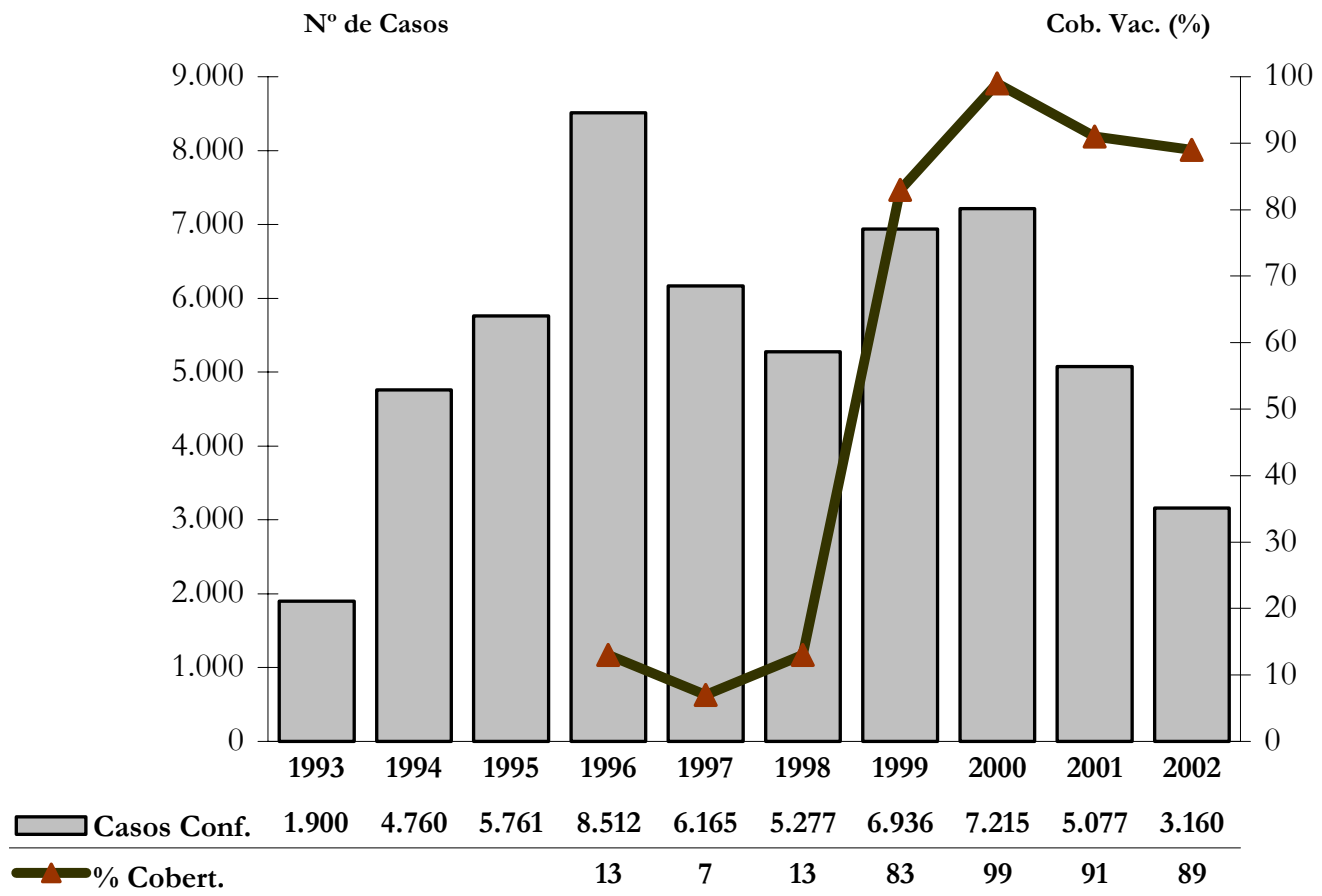

Fonte: Ministério da saúde, 2003

Assim conclui-se que no Brasil, através do desenvolvimento tecnológico, ou seja, através do processo de inovação impulsionado e articulado pelo Governo, tornou-se possível a ligação entre o desenvolvimento da Ciência nos meios acadêmicos, passando-se pelos Laboratórios públicos de pesquisa, até que se chegasse ao produto industrial (a produção em larga escala de vacinas).

\section{2. $O$ caso da vacina recombinante contra a hepatite $b$}

O vírus da Hepatite B foi descoberto em 1965 pelo Dr. Baruch Blumberg, laureado com o prêmio Nobel por esse feito. Quatro anos após a descoberta do vírus da Hepatite B, juntamente com o microbiologista Irving Millman, desenvolveu a primeira vacina contra a Hepatite B. ${ }^{41}$

No Brasil, a produção da vacina recombinante contra a Hepatite B, foi conduzida pelo Instituto Butantan, mais especificamente em seu Centro de Biotecnologia. É o segundo

\footnotetext{
${ }^{41}$ Hepatitis B Foundation. Disponível em: www.hepb.org/professionals/hepatitis b vaccine.htm Acesso em: 01 nov. 2006
} 146 
produto recombinante produzido no Brasil (sendo o primeiro a insulina, produzido pela Biobrás) e considerado a primeira vacina recombinante de produção nacional. Foi desenvolvida em parceria do Centro de Biotecnologia, com a Divisão Bioindustrial e pesquisadores russos. ${ }^{42}$

Em 1993, a partir de um acordo entre o Centro de Biotecnologia e um pesquisador da antiga União Soviética, iniciaram o processo de P\&D para a produção da primeira vacina recombinante no Brasil. Em 1998, com os testes em seres humanos já iniciados, a produção do Instituto Butantan chegou a cinco milhões de doses, com a perspectiva de duplicação de produção em 1999. Mas, devido à fraca infra-estrutura do país que limitou os testes clínicos, somente a partir de 2001, com uma demanda de um milhão de doses do PNI (Programa Nacional de Imunizações), é que houve a estimativa de alcançar uma produção superior a trinta milhões de doses. De acordo com o próprio Instituto Butantan, hoje a capacidade instalada é de uma produção de cinqüenta milhões de doses por ano (Gadelha e Azevedo, 2003).

A produção nacional da vacina $\mathrm{HB}$, foi impulsionada por vários fatores, entre eles, o grande interesse dos cientistas em dominar o conhecimento da área de tecnologia de recombinação genética; a hepatite era um sério problema de saúde pública no Brasil; os gastos com a importação da vacina HB representavam 73\% do gasto nacional com a importação de vacinas; e, por último, o apoio recebido do Ministério da Saúde, que se comprometeu a comprar a vacina. O Instituto Butantan foi o único a receber financiamento para o desenvolvimento dessa atividade, recebendo recursos da FINEP ${ }^{43}$, do $\mathrm{CNPq}^{44}$, e da Fapesp ${ }^{45}$ (Gadelha e Azevedo, 2003).

\subsection{Passagem do objeto conhecimento ao objeto industrial: a importância da} técnica

Como já demonstrado anteriormente no presente artigo, o governo tem desempenhado políticas voltadas para a diminuição da lacuna entre o conhecimento acadêmico (ciência) e as necessidades industriais, com referência à produção de fármacos no Brasil.

42 Instituto Butantan. Série Didática - Número 7. Biotecnologia no Instituto Butantan. Disponível em: www.butantan.gov.br/materialdidatico/numero7/numero7.pdf. Acesso em: 04 out. 2006.

43 Financiadora de Estudos e Projetos

${ }^{44}$ Conselho Nacional de Desenvolvimento Científico e Tecnológico

${ }^{45}$ Fundação de Amparo à Pesquisa do Estado de São Paulo 
De acordo com Mignot e Poncet (2002), da codificação do conhecimento científico até a obtenção de produtos e processos industriais é necessário um aumento da integração das técnicas. Assim, surgem duas novas tendências: a industrialização do conhecimento e a tecnicização do conhecimento. Trazendo a produção acadêmica próxima das necessidades industriais, sendo a técnica a "dobradiça" que une essas duas tendências.

Por isso, o processo de inovação se dá através da interação entre vários agentes. Começando pela área da pesquisa, passando pela técnica e, por fim, chegando ao processo de industrialização.

\subsection{Objeto Conhecimento}

A importância da relação entre universidade-empresa, já foi explicada como de suma importância para o início do processo de inovação. Os investimentos em $\mathrm{P} \& \mathrm{D}$, portanto, têm um papel central na produção de conhecimento.

Cada vez mais a indústria farmacêutica tem demandado conhecimento científico, proveniente dos meios acadêmicos para a produção de novos produtos e processos.

A produção da vacina recombinante contra a Hepatite B ilustra como a pesquisa científica e as empresas podem relacionar-se. Do ponto de vista acadêmico, o estudo do vírus da Hepatite B e sua forma de atuação nas células do fígado é o que constitui o objeto de estudo da biologia molecular. Do ponto de vista das empresas, existe a possibilidade de aplicar esse conhecimento e as técnicas relacionadas a ele, na produção industrial e vacina.

Esses dois lados tão distintos do setor econômico (o acadêmico - detentor do conhecimento, e o industrial - detentor do capital), têm dificuldades de se organizar no cenário brasileiro. Uma das razões é o fato de que, o setor industrial se preocupa exclusivamente com resultados (ou seja, lucros), enquanto que no acadêmico esse não é um objetivo tão previsível. Mas existem algumas exceções no Brasil. O laboratório Aché, possui uma equipe de nove pesquisadores que fazem essa ligação entre a empresa e o meio acadêmico. Na Inova (Agência de Inovação da UNICAMP) desde sua fundação foram firmados 130 contratos de transferência de tecnologia, foram licenciadas 45 tecnologias (maior parte no setor farmacêutico, médico e químico), foram depositadas 153 patentes, registradas 22 marcas e desenvolvidos 24 softwares. Além do exemplo da Ybios, que é uma empresa nacional formada por uma joint-venture entre Centroflora, Natura e Orsa Floresta. 
Este último sendo um exemplo do próprio setor industrial investindo em pesquisa. (Revista Exame, 2006). ${ }^{46}$

No caso da Vacina recombinante da Hepatite B, produzida pelo Instituo Butantan, o resultado foi fruto de uma parceria do Centro de Biotecnologia com a Divisão Bioindustrial e pesquisadores russos. Foram estudadas as células do fígado infectado pelo vírus HB. Um fígado infectado pelo vírus HB pode evoluir para uma cirrose, que pode aumentar o tamanho do fígado, fazendo com que se perca sua textura lisa, ficando endurecido e adquirindo aspecto nodular. Essa cirrose pode evoluir para um câncer de fígado, mais conhecido como carcinoma hepatocelular (LIEBER) ${ }^{47}$.

É necessário ressaltar que sem os investimentos em P\&D realizados pelo governo no Instituto Butantan e a parceria, não seria possível a detecção e entendimento da evolução da doença e, consequentemente, a produção de sua vacina. Vale a pena citar os resultados que DOSI (1988) utiliza para a construção de um modelo alternativo sobre o processo de inovação, com respeito ao objeto de conhecimento. Para ele são quatro resultados: os inputs científicos têm um papel crescente no processo de inovação; as atividades de P\&D apresentam uma crescente complexidade que faz com que o processo de inovação seja objeto de planejamento de longo prazo pelas empresas e outros agentes, o que faz pensar na hipótese de uma inovação como resposta dos produtores frente às mudanças nas condições do mercado; existe uma significativa correlação entre esforço de P\&D e output inovador em muitos setores; também se observa uma ausência de correlação evidente entre mercado e padrão de demanda por um lado e output inovador do outro; a crescente formalização institucional da investigação, mesmo conservando uma natureza intrínseca incerta, indicaria a existência de um conjunto de eleições tecnológicas que são conhecidas ex-ante.

A partir do exposto acima, verifica-se que através da parceria entre o Instituto Butantan e pesquisadores estrangeiros é que se pôde constatar o papel desempenhado pela Ciência no entendimento do funcionamento da estrutura do DNA, aplicado no caso da Hepatite B. O desenvolvimento da Ciência, dentro dos laboratórios públicos de pesquisa, é o ponto inicial para se entender o processo de inovação na indústria farmacêutica, voltada para a produção de vacinas mais especificamente a vacina recombinante contra a Hepatite B. Ainda cabe ressaltar a importância dos laboratórios de pesquisa na produção do

46 Revista Exame. Ciência Combina com Lucro. Publicado em 22 nov. 2006, Edição 881 - Ano 40 - n 23 , Ed Abril

47 Lieber, S.R. Saiba Mais Sobre as Hepatites Virais. Disponível em: www.mackenzie.com.br/universidade/exatas/boletim/saiba mais/hepatite.htm. Acesso em: 04 out. 2006. 
conhecimento. Nesse sentido, o objeto conhecimento da biologia molecular, para o caso em pauta, são as células do fígado infectadas com o vírus da Hepatite B. Através desse conhecimento é que se consegue chegar numa técnica de desenvolvimento de uma vacina para posterior aplicação na sociedade, através de uma produção em larga escala.

\subsection{Objeto Técnico}

A técnica que permitiu o estudo das células do fígado infectadas pelo vírus HB foi a técnica do DNA recombinante. Essa técnica consiste na clonagem molecular, que consiste no isolamento e propagação de moléculas de DNA idênticas. São duas etapas importantes: O fragmento do DNA de interesse, chamado de incerto, é ligado a uma outra molécula de DNA, chamada de vetor, formando o que é conhecido como DNA recombinante. A molécula do DNA recombinante é introduzida numa célula hospedeira compatível, em um processo chamado de transformação. A célula hospedeira que adquiriu a molécula do DNA recombinante é agora chamada de transformante ou célula transformada. Um único transformante, em condições ideais, sofre muitos ciclos de divisão celular, produzindo uma colônia que contêm milhares de cópias do DNA recombinante. ${ }^{48}$

No caso da vacina da Hepatite B, vale a pena ver os detalhes de sua técnica, desenvolvida dentro do Instituto Butantan: A vacina é produzida inserindo-se múltiplas cópias do gene que codifica a proteína HBsAg do vírus da Hepatite B, no cromossomo de uma levedura. Em condições especiais, esta proteína é expressa em alta quantidade pela cultura de leveduras. A proteína HBsAg tem a capacidade de formar uma estrutura idêntica a de uma partícula viral (virus-like particle), no entanto, sem conter o material genético viral. Esta partícula é imunogênica e induz a produção de uma resposta imune protetora, principalmente de anticorpos. Para a produção da vacina, a levedura é quebrada, as partículas são purificadas e usadas na formulação da vacina do Butantan. ${ }^{49}$

No caso da indústria farmacêutica em geral vale a pena ressaltar as fases pelas quais o processo de inovação tem que passar desde a pesquisa passando pela técnica, até chegar à produção: a fase 1 da pesquisa fundamental é aquela na qual os laboratórios procuram descobrir um princípio ativo. Nesta fase, os químicos e farmacologistas podem utilizar um método chamado screening, que consiste em fazer vários testes discriminantes, extremamente

\footnotetext{
48 Mucillo, D. et all Tecnologia do DNA Recombinante. Disponível em: www.enq.ufsc.br/labs/probio/disc eng bioq/trabalhos pos2004/dna/index.htm. Acesso em: 20 out. 2006. 49 Instituto Butantan. Série Didática - Número 7. Biotecnologia no Instituto Butantan. Disponível em: www.butantan.gov.br/materialdidatico/numero7/numero7.pdf. Acesso em: 04 out. 2006.
} 
específicos, eliminando aqueles que não apresentarem resultados positivos. Uma vez selecionadas em torno de 20 substâncias entra-se na fase de desenvolvimento pré-clínica, onde se testam os candidatos medicamento, por meio de testes biológicos in vitro e, por meio de experimentações em animais (cobaias). Procede-se então, paralelamente aos testes farmacológicos e toxicológicos a fim de determinar a ação exercida pela substância estudada (mortalidade, efeitos de uma administração prolongada, efeitos secundários). Passa-se então à fase mais crítica do processo de inovação, aquela do desenvolvimento clínico no homem.

Estes testes clínicos são realizados em três fases. Na fase I (farmacologia clínica), procura-se determinar a dose tolerada e o esquema de administração sobre um pequeno número de voluntários saudáveis. Na fase II, verifica-se a "eficacidade" terapêutica (fase IIa) do candidato medicamento, determinam-se então as posologias e tenta-se detectar os principais efeitos secundários (fase IIb) sobre um grande número de doentes (geralmente em torno de 100 a 300). Enfim, na fase III estudos prolongados são levados sobre uma grande amostra (geralmente entre 1.000 e 3.000 indivíduos), a fim de medir a segurança normal e a eficiência do emprego do medicamento testado. No final desta fase crucial, o medicamento retido (apenas 10\% dos produtos que entraram na fase I chegam à fase III - o restante é rejeitado) poderá ser avaliado pelas autoridades sanitárias num quadro de uma demanda de autorização para colocar no mercado, após a inspeção da farmacovigilância (ou fase IV), conforme Fonseca $(2006)^{50}$.

De acordo com Mignot e Poncet (2002), no campo da biologia, o processo da tecnicização do conhecimento estabeleceu uma continuidade entre a descoberta da estrutura do DNA e o estudo do genoma. Esse desenvolvimento se deu, especialmente, dentro dos laboratórios públicos de pesquisa, ao mesmo tempo em que as indústrias integravam o conhecimento à técnica, fundamentando as bases da engenharia genética. Conforme ressaltado por eles: "These two movements, products of two very different organizational structures (public research institutions and private companies), mutually support each other through transfers that take place between the two environments (academic and industrial). However, the products resulting from biomolecular engineering techniques open onto potential growth markets (agriculture, medicine or the pharmaceutical industry)".

Assim, a passagem do conhecimento acadêmico para a aplicação industrial necessita da finalização desse conhecimento, sendo transformado em técnicas. Os elementos da técnica

${ }^{50}$ Fonseca, J.W.F. Trajetória Tecnológica e Processo de Inovação na Indústria Farmacêutica. Pesquisa em andamento, 2006. 
devem ressaltar a aplicabilidade do conhecimento científico na produção industrial. Com isso, torna-se fundamental o papel da técnica atuando como uma ponte entre o conhecimento científico e a exploração industrial do mesmo. A técnica tem, portanto, um papel central no processo de inovação. Pode-se dizer que a técnica é que torna possível a aplicação do conhecimento da Ciência no desenvolvimento de novos produtos.

Enfim, a técnica parece ser o centro do processo inovativo, permite que os pesquisadores, nos laboratórios públicos, apliquem seu conhecimento adquirido na pesquisa de uma maneira pré-determinada para que a produção em escala industrial seja viável. Assim, a técnica é um lugar de passagem obrigatório, sem o qual, todo conhecimento seria um fim em si mesmo, onde a população não poderia usufruir os benefícios advindos da produção de produtos inovativos, no combate a diversas doenças, por exemplo.

\subsection{Objeto Industrial}

Chega-se ao último ponto de análise do processo de inovação nas biotecnologias: a produção em escala industrial da vacina recombinante da Hepatite B.

Uma vez pesquisados os efeitos da infecção do vírus da hepatite B nas células do fígado, o desenvolvimento da tecnologia recombinante para a produção da vacina contra a hepatite B e, por fim, aplicado o conhecimento adquirido com a pesquisa através de técnicas, resta a produção do produto em escala industrial.

No caso da vacina recombinante da hepatite B, foi devido a uma demanda do PNI (Programa Nacional de Imunizações) que se tornou possível a produção industrial da vacina produzida pelo Instituto Butantan. Hoje a capacidade de produção de vacinas contra a hepatite B é de 50 milhões de doses por ano, sendo em sua maioria compradas pelo Ministério da Saúde para atender à demanda para imunização da população brasileira.

Para que se chegasse a esse nível de desenvolvimento de inovação, a indústria farmacêutica teve que estabelecer estratégias organizacionais conforme segue abaixo: Primeiramente, os laboratórios farmacêuticos adotaram métodos de pesquisa mais dedutivos, formalizados e planificados, conforme Dousset (1995) e Dumoulin (1994) ${ }^{51}$. Neste quadro, os pesquisadores procuram utilizar os conhecimentos relativos às causas das desordens humanas, às propriedades dos componentes químicos dos medicamentos e suas ações nos organismos humanos para conceitualizar a estrutura de uma molécula ideal, o que leva a uma renovação da pesquisa. Em segundo lugar, as indústrias farmacêuticas procederam a uma verdadeira

${ }^{51}$ Dousset, J.C. Histoire des medicaménts des origines à nos jours. Ed Payot, Paris, 1985. 
reorganização da pesquisa com a constituição de equipes cada vez mais interdisciplinares (toxicologia, clínica, biologia molecular, química, bioquímica, farmacodinâmica, etc.), capazes de utilizar conhecimentos científicos ao mesmo tempo interativos e evolutivos, no sentido de Nelson \& Winter. Por fim, a idéia de que o processo de inovação deveria ser considerado como um processo principalmente linear, mas integrando igualmente feed-backs entre as diferentes etapas de uma cadeia central de inovação (indo da pesquisa fundamental à comercialização, passando pelo desenvolvimento e a produção), assim como as interações entre a produção e a esfera científica, pouco a pouco fez seu caminho, questionando a lógica tradicional (linear) da inovação farmacêutica. (Fonseca, 2006).

No caso do Brasil, a partir da verificação do grande impacto da Hepatite B, na população - estima-se que 15\% dos brasileiros já tiveram contato com o vírus da Hepatite B (Ministério da Saúde, 2003) - surgindo a necessidade de uma campanha com abrangência nacional. Essa abrangência nunca seria possível devido ao preço das doses da vacina que eram importadas.

Através de políticas que favoreciam o ambiente interno, com foco na produção de conhecimento e desenvolvimento de novas técnicas (com modernização dos laboratórios públicos), é que se possibilitou a produção em larga escala da Vacina recombinante contra a Hepatite B.

Hoje o Instituto Butantan tem capacidade de produzir 50 milhões de doses de vacinas de Hepatite B, tornando possível o barateamento do produto (antes importado) e sua conseqüente viabilidade como produto integrante da medicação básica do Ministério da Saúde. Tendo assim, a possibilidade de levar a vacina para todas as populações, especialmente as mais carentes, que não tinham acesso à vacina devido ao custo elevado. Atualmente a cobertura da vacinação contra a Hepatite B chega perto dos 100\% em menores de 1 ano no Brasil. Pode-se dizer que o Estado desempenhou de maneira eficiente seu papel social, através de políticas de saúde, com relação ao alcance dessa vacina.

\section{Conclusão}

O objetivo deste artigo foi analisar o processo de inovação nas biotecnologias, através de uma análise do caso da Vacina contra Hepatite B produzida no Instituto Butantan.

Analisou-se o papel do governo através de incentivos, tanto na área de financiamento, quanto na área fiscal, burocrática e estabelecimentos de várias políticas de ordem econômica que estimulem o desenvolvimento da biotecnologia na área farmacêutica. O papel do Estado como articulador do ambiente propício para o desenvolvimento da 
inovação na área de biotecnologia, fica evidenciado no estudo de caso, e verificando-se os resultados obtidos no nível da cobertura vacinal da hepatite $\mathrm{B}$ e sua relação direta com a diminuição dos casos confirmados dessa doença.

Ficou demonstrada também a evidente importância dos laboratórios públicos de pesquisa para a produção do conhecimento, necessário para o início do processo de inovação. Além da evidente junção entre o setor público e o privado na aplicação da técnica de pesquisa. A técnica se sobressaindo nessa análise como ponto obrigatório e, ao mesmo tempo, de ligação entre o setor privado e o público, ou melhor, entre o objeto de conhecimento e o objeto industrial. E, finalmente, através do Estudo de Caso da Vacina Recombinante contra a Hepatite B produzida no Instituto Butantan pôde-se ilustrar essas diversas fases do processo de inovação, onde o Instituto Butantan, sendo um laboratório financiado com dinheiro público através de parcerias desenvolveu a técnica necessária para a produção em larga escala dessa vacina.

Com isso, identificou-se que para que ocorra a inovação nas biotecnologias, voltada para a produção da vacina contra a hepatite $B$, não há outro caminho a não ser a passagem do conhecimento - através dos altos investimentos em P\&D e as parcerias público-privada para a produção industrial, sendo a técnica de vital importância para a viabilização desse produto. Destacando-se o desenvolvimento da técnica do DNA recombinante como fundamental para o desenvolvimento da vacina recombinante. Somente a partir da descoberta dessa técnica da biologia molecular é que se possibilitou o estudo e desenvolvimento de produtos baseados em tecnologia recombinante. 